\title{
KNOWLEDGE MANAGEMENT FOR VIRTUAL TEAMS
}

\author{
Anne Shepherd, Robert Morris University, vasst262@mail.rmu.edu \\ James Cooper, Robert Morris University,jecst232@mail.rmu.edu
}

\begin{abstract}
As organizations create and evolve their digitization and future workforce strategies, knowledge management becomes an important consideration in building an evolutionary digital strategy. A pivot point has emerged in how organizations use knowledge to achieve agility, innovation and competitiveness in the digital world. Virtual teams open new possibilities and challenges for knowledge creation and sharing in organizations. Tacit and explicit knowledge transfer is fundamental to effective knowledge management in a rapid paced digital world. This research studies the factors influencing knowledge creation and knowledge sharing in a high velocity, networked environment.
\end{abstract}

Keywords: Knowledge management, Virtual Teams, Distributed Worker, Tacit knowledge

\section{INTRODUCTION}

As mobility proliferates in the workplace, organizations are challenged to share knowledge across a geographically dispersed and diverse workforce. Knowledge is defined in this paper as the individual's experiences, beliefs, values, culture, and "know how" (Davenport \& Prusak, 1995). Knowledge is tacit, experience based, or explicitly documented and articulated (Rai, 2011). A virtual team also referred to as geographically dispersed or remote teams, are individuals who work from different locations including alternate locations away from the company office. Virtual teams participate in ideation, and sharing knowledge, opinions and experience (Davidekova \& Hvorecky, 2016). Virtual leaders and teams are commonplace in organizations and growing. Organizational leaders and teams are faced with the dilemma of integrating knowledge across the virtual team to deliver solutions and solve problems with agility. Organizations rely on virtual teams for mission critical operations and favorable performance results.

Virtual teams are expected to have the knowledge to rapidly develop high caliber solutions. In a dispersed help desk operation, for example, customer service agents frequently collaborate and share knowledge to quickly resolve problems and engender more than a satisfactory customer experience. Another example are software development teams that individually develop and test software code components. Software developers transfer tacit and explicit knowledge as the product is codified, integration tested and prepared for production. The Internet fueled networked organization, coupled with the pace of information transactions and change, has created a highly interconnected virtual workforce with "virtual communication central to everyday life in companies and organizations" (Davidekova \&Hvorecky, 2016, p. 96). Hoffman (2016) states we are at a tipping point in how organizations use knowledge. Artificial intelligence offers the possibility of creating a knowledge network connecting human intelligence with machine intelligence. While machine intelligence opens up new possibilities, Winston (2011) asserts that all knowledge is about storytelling, and only people can build deep symbolic descriptions of situations and events. Polanyi (2005) states "we know more than we can tell". People have years of experience that is the foundation of tacit or silent knowledge. The individual tacit knowledge existing across virtual teams created through years of experience is crucial to organization performance and competitiveness.

The purpose of this paper is to research virtual teams and the factors that affect knowledge creation and knowledge sharing in a networked world. According to Deloitte (2015), by 2025 an estimated $75 \%$ of employees will be millennials and Generation Y, the digital natives under 32 years old. This new workforce has grown up as digital natives, familiar with the Internet and computers, in a networked world. The implication of knowledge management for the digital culture (i.e. millennials and digital natives) is unknown. Deloitte (2015) hypothesizes the knowledge workers and virtual team's ability to learn new things will be an important aspect of knowledge management. Teams are the key building block of competitive organizations (Kanawattanachai \& Yoo, 2007). Forward thinking organizations will adopt knowledge management strategies for the future workforce to sustain competitiveness. 


\section{LITERATURE REVIEW}

\section{Virtual Team Characteristics}

The characteristics of virtual teams influence how the teams create and share knowledge. Davideko and Hvorecky (2016) state virtual teams have interdependent tasks, limited face to face interaction and depend on communication technology. Virtual teams focus on communication and trust to accomplish organization goals (Bosch-Sijtsma, Fruchter, Variainen \& Ruohomaki, 2009). In virtual teams, trust stems from the reliability and competence of team members. Task interdependence is prevalent in virtual teams, a finding from the case analysis conducted by BoschSijtsma et al (2009). Virtual teams rely heavily on technology and the Internet to support communication and overcome geographic distance barriers. Bosch et al (2009) also found that years of experience and domain expertise influence the performance of a virtual team. Geographically distributed virtual teams need time to adjust to the context when sharing knowledge. This adjustment process makes it difficult to convey meaning and share knowledge. A common language and mental model can facilitate knowledge sharing. Semeradova (2015) states that a common language positively effects the team's shared vision and the trustworthiness of shared information. Davenport (2001) points out that to learn and transfer knowledge teams need reflection time, particularly dispersed virtual teams. The knowledge management spiral circulates knowledge from tacit to explicit and through reflection creates new tacit knowledge (Nonaka \& Takeuchi, 1995). In virtual teams, experience is transferred and knowledge flows from tacit to explicit as the team communicates and works together on tasks (Nonaka \& Takeuchi, 1995).

\section{Knowledge Creation and Sharing}

Knowledge creation happens through interactions among individuals and organizations. Nonaka (Nonaka and Takeuchi, 1995) refers to knowledge creation as establishing an organization's "ba", a shared space where knowledge is created. The interaction, an interactive spiral, integrates tacit and explicit knowledge (Nonaka \& Takeuchi, 1995). Tacit knowledge is individual experience-based knowledge in the mind, expressed as "know how". Explicit knowledge is knowledge that is documented such as processes and procedures. Knowledge creation begins as tacit knowledge and through the sharing and conversion process is transferred to explicit knowledge. The knowledge creation and sharing cycles continues and new tacit knowledge is created (Rai, 2011). Kanawattanachai and Yoo (2007) stated that knowledge sharing and coordination in virtual teams can be problematic due to the geographic dispersion of knowledge. The virtual team has to be aware of individual knowledge to seek access to the knowledge. Additionally, the virtual team has to trust the knowledge's veracity and the professionalism and reliability of the team member transferring the knowledge (Kanawattanachai \& Yoo, 2007). Virtual teams are challenged to share and create knowledge because of their distance and the lack of in person face-to-face contact. Nonaka asserts the socialization or "originating ba" is fundamental to transferring tacit knowledge and shared experiences among team members (Nonaka and Takeuchi, 1995). Polanyi (2005) posits that all knowledge is tacit and therefore knowledge circulation begins with individual tacit knowledge. Missing personal contact, the virtual team has difficulty sharing tacit knowledge (i.e. know-how). Organizational culture being another key factor in reinforcing knowledge creation and transfer as it influences how virtual team members learn, acquire and share knowledge (Alvai and Leidner, 2001). Organizational culture forms from the beliefs, values, mental models and symbols of the organizations. In co-located teams, the organization can foster cultures of knowledge sharing and hands-on experiential learning (Rai, 2011). In virtual teams, the team dispersion and possible lack of history together as a team complicate building a knowledge management culture. For instance, a manager observed that help desk employees who telework and have not built trust within the team are less inclined to share real world experiences to improve knowledge management articles and procedural documents. Bosch et al (2009) state "diversity and disparity in skills, knowledge, abilities, and experiences for distributed teams can negatively impact knowledge transfer" (p. 300). Virtual teams can miss the shared mind-set that enables knowledge to flow from one member to another.

\section{Social Media and Technology}

Social media and other technology tools can serve as an intermediary to bring together virtual team member's demand for and supply of knowledge. The virtual team model's prevalence is a consequence of technology advances and the Internet. Without technology, communication across a distributed team would be almost impossible at the current pace of information exchange. Tools for communication and videoconferencing are necessary for virtual team collaboration and knowledge sharing and transfer. Alvani and Leidner (2001) state that information technology can support knowledge management in various ways (p.26). Knowledge management today inevitably involves technology; technology enables tacit knowledge exchange. Social media and digital technology promote knowledge sharing, 
knowledge creating and connects people (Pawlowski et al, 2014). Social media forms facilitate communication from one individual to another, connecting language and meaning. Social media offers an informal communication channel for knowledge transfer. Chat rooms for example allow the spontaneous flow of knowledge and the creation of new knowledge (Semeradova, 2015). The online tools allow the information that is shared to be captured in its native form. Through social media the virtual team can share their domain expertise and capture tacit knowledge that may not be captured in a knowledge management repository. Wearable devices worn by people can be used to simulate experiences and accelerate skills development, knowledge transfer and deep learning, and hands-on development (i.e. know-how). Another advantage social media offers is fostering a community of sharing among the virtual team members. Millennials and digital natives incorporate social media and interactive devices into their daily lives. This technology supports knowledge creation and transfer. Through blogs, chat sessions, and other social interactions data is being converted to information and knowledge continuously. While noise has to be filtered from the continuous data and information flow, new knowledge is created and shared in the communication process. In addition to social media, knowledge repositories are a tool for knowledge transfer. Microsoft Sharepoint is a tool implemented in organizations to store business documents and to collaboratively share information among teams. In Semeradova's (2015) research, a platform storing knowledge with editable wikis was used to classify knowledge for easy use by a project team. The platform included a newsfeed which increased awareness by alerting the team to new wiki entries.

\section{Knowledge Management Challenges}

Table 1 summaries the types of workers that typically comprise a virtual team and the knowledge management challenges they face. Virtual teams work in different locations and can be comprised of employees working from home, a satellite location or in another country. A virtual team can be formed with one or all types of dispersed workers. Table 1 presents the challenges virtual teams encounter from a knowledge management context.

Table 1. Knowledge Management Challenges for Virtual Teams

\begin{tabular}{|c|c|c|}
\hline Category & Definition & \begin{tabular}{|l} 
Primary Knowledge \\
Management Challenges
\end{tabular} \\
\hline Teleworker & $\begin{array}{l}\text { Individual works from alternate } \\
\text { location from company site (i.e. } \\
\text { home). Individual typically has } \\
\text { worked in office setting prior to } \\
\text { teleworking }\end{array}$ & $\begin{array}{l}\text { - IT technology to link with team members } \\
\text { - Trust is a lesser challenge if the teleworker has } \\
\text { previously worked with the team face-to face }\end{array}$ \\
\hline $\begin{array}{l}\text { Geographic } \\
\text { dispersed } \\
\text { worker }\end{array}$ & $\begin{array}{l}\text { Individual works at company site } \\
\text { in different locations }\end{array}$ & $\begin{array}{l}\text { - Language and culture, particularly in } \\
\text { international setting } \\
\text { - Building trust } \\
\text { - Mental model } \\
\text { Socialization and sharing "know how" }\end{array}$ \\
\hline $\begin{array}{l}\text { External worker } \\
\text { or contractor }\end{array}$ & $\begin{array}{l}\text { Individual employed by another } \\
\text { company and supports the virtual } \\
\text { team to deliver products and } \\
\text { services }\end{array}$ & $\begin{array}{l}\text { Trust to share knowledge } \\
\text { with individual external to } \\
\text { the company } \\
\text { - Mental Model } \\
\text { - Awareness of knowledge }\end{array}$ \\
\hline
\end{tabular}

Source: Adapted from Pawlowski et al (2014)

The research questions for the study are:

- What are the factors that influence knowledge creation for virtual teams in a digital environment?

- What factors influence knowledge sharing in virtual teams? 


\section{RESEARCH METHODOLOGY}

\section{Framework for Knowledge Management in Virtual Teams}

The allied concurrent engineering framework (Figures 1 and 2) are used to study knowledge management for virtual teams in a networked world. Allied concurrent engineering is a distributed and collaborative engineering process, where individuals from different disciplines and different companies virtually design and develop products (Wang, Chen, Chen, \& Ho, 2005). Allied concurrent engineering practitioners share product and process knowledge. The systematic approach in product delivery and interaction provides a quick response to customer expectations. Trust and sharing across multi-functional teams is foundational to concurrent engineering.

Explicit forms of knowledge within the allied concurrent engineering framework are Activities, Interaction knowledge, Constraint knowledge and Reference knowledge. The Knowledge Management Framework (KMFvT) for Virtual Teams diagram (Fig 1) shows the flowing of knowledge information and sharing. This study defines Activities knowledge as a derivative of the daily activities of the organization such as meetings, brainstorming from all team members virtual or physically located on site. It's important to distinguish Activities from Activity within the framework, the Activity is a collection of all the explicit knowledge activities. Activity Knowledge, which is the end product after the "Flow Knowledge Item" is the tacit "experienced based" knowledge and organization intellectual property.

Interaction knowledge is the interaction of individual, teams or a group or division. This knowledge must be shared throughout the organization, the organization cannot create knowledge devoid of individuals, but if the knowledge is not shared at the group level it does not spread throughout the organizations, (Nonaka, Takeuchi, 1995, p.225). Constraint knowledge is in the form of government publications, regulatory authoritative documentation, and corporate policies. Last of the explicit knowledge is Reference knowledge which is in the form of repositories for organizing and storing information, its forms are wikis, SharePoint, and web portal form. Reference knowledge is structured in form and easily searchable. These forms of knowledge Activities, Constraint, Interaction and Reference knowledge flow bi-directional from the Flow Knowledge Item repository. The Flow Knowledge Item is Activity knowledge which encompass all activities of the explicit knowledge form discussed. The flow of tacit and explicit knowledge through the KMFvT enables information sharing and management of knowledge (Wang et al, 2005).

\section{Knowledge Management Framework}

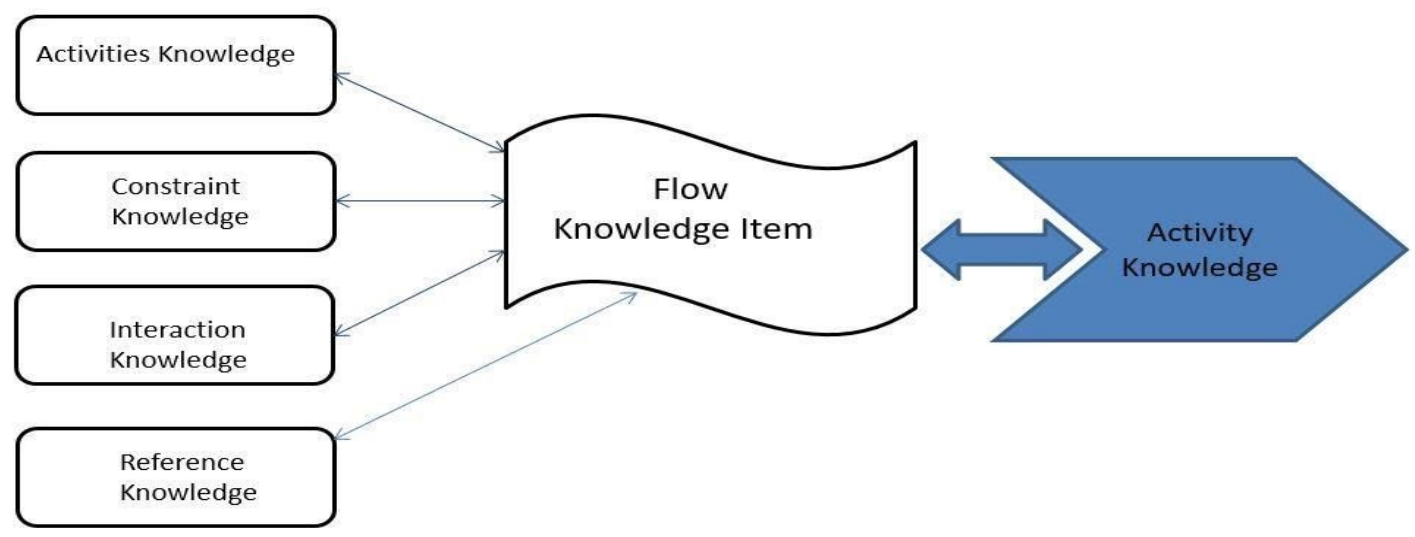

Source: Adapted from: Wang et al (2005).; Methodology and system framework for knowledge management in allied concurrent engineering

Figure 1. Knowledge Management Framework

Both the Knowledge Management Framework (KMFvT) and Distributed Knowledge Management frameworks provide a repository for capturing tacit knowledge from explicit knowledge. The Distributed Knowledge 
Management Framework (Figure 2) takes Project Management knowledge such as software deliverable versions or product knowledge and distributes the information. In this model Product Knowledge encompass all the distributed knowledge sources such as Team Knowledge Management, Collaborative Activity Knowledge Management, Process Knowledge Management, and Personal Knowledge Management. The Product Knowledge takes the form of tacit knowledge.

Team Knowledge Management has several teams working with a shared goal to develop a tangible or intangible item. Collaborative Activity is the activities of different teams in the forms of reports, deliverable, communications. These are in the form of both tacit and explicit knowledge. Process Knowledge Management is developed from current processes, changes and modification to existing process for improved performance. Personal knowledge Management is the tacit knowledge of subject matter experts, derived from processes and experience historically.

\section{Distributed Knowledge Management Framework}

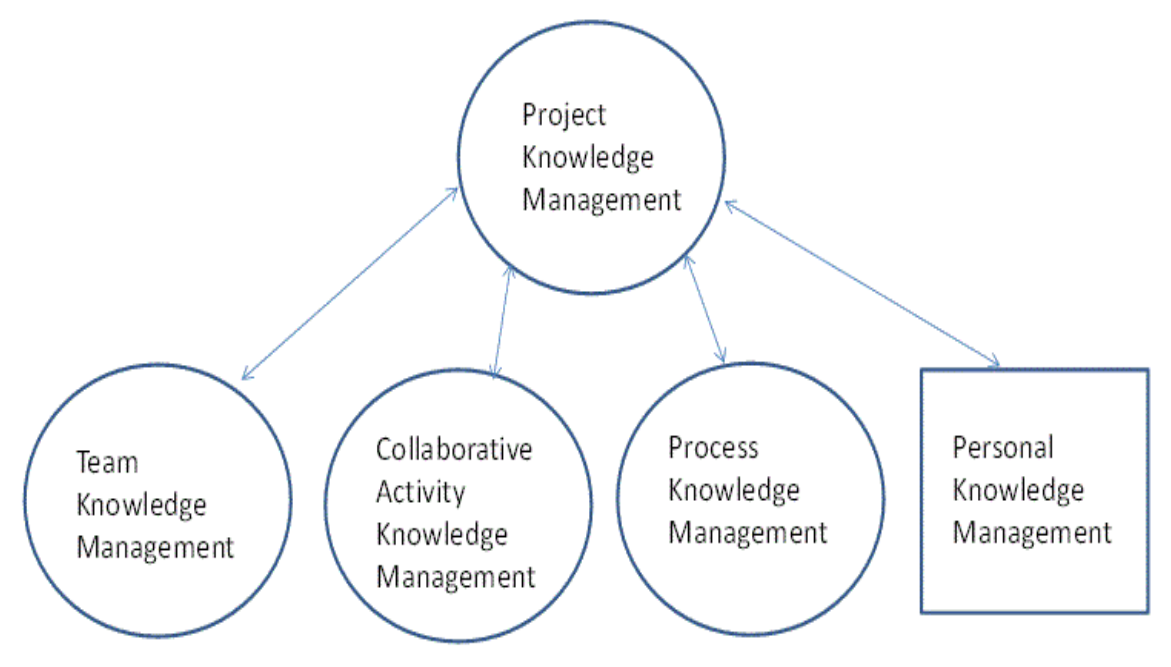

Source: Adapted from: Wang et al (2005). Methodology and system

framework for knowledge management in allied concurrent engineering

Figure 2. Distributed Knowledge Management Framework

The study will use a qualitative case study method and focus group teams to research the knowledge creation and sharing in virtual teams. We will study knowledge management strategies and implementation at a government agency and a private industry firm, specifically focusing on approaches with the new workforce of millennials and digital natives. In the research study, we will observe virtual team behavior to understand the culture, how they create and share knowledge, and the technology and tools used. The research will study virtual teams with digital natives and examine how and the degree to which they share knowledge.

The qualitative study employs focus groups of 4 virtual teams with millennials and digital natives on the team. data. The virtual team consists of 8 or more participants. The study uses the allied concurrent engineering frameworks to analyze and compare knowledge management strategy and implementation in a virtual setting. The focus groups topics are enablers and barriers for knowledge sharing and creation, experiences with social media for knowledge management, culture and trust. The data analysis method will incorporate thematic analysis. The results and findings from the research will be published in a future paper. 


\title{
DISCUSSION
}

\begin{abstract}
Knowledge Management for Next Generation Virtual Teams
Thomas and Bostrom (2010) quote Menken who states that "It is mutual trust even more than mutual interest that holds human associations together". Menken's quote aligns with Polanyi (2005) and Davenport's (1995) views about trust and knowledge sharing. Trust is foundational for virtual teams to create and share knowledge. The next generation millennials and Generation Y digital natives embody values of cooperation, trust and sharing. The impetus for the sharing economy fueled by the next generation's, who were born after 1990, desire to share resources as illustrated with AirBNB (shared housing) and Uber (shared transportation). However, there may be situations where incentives are necessary to nudge virtual teams to share knowledge. Additionally, Cummings and Dennis (2018) assert that social media information utilized to form first impressions among virtual teams can affect future team interactions and possibly knowledge sharing.
\end{abstract}

This cooperative mindset for sharing will reshape how organization's approach knowledge management and communities of practice in the future. Knowledge management for the future must integrate quality assurance protocols for knowledge management exchange within the communities. For example, virtual learning communities who join for a common interest adopt some methods for evaluation combining the tacit and explicit knowledge of community members. This is not a recommended hierarchy structure, but interaction knowledge as deliberated in the knowledge management framework for virtual teams. A virtual team may foster advancement of building collective wisdom, and learner goals and acquire the abilities of how to learn at higher levels. (Wang, Chen, Chen, \& Ho, 2005) Stories and narratives provide rich descriptions of past actions and experiences. Stories told through YouTube, webinars and other video technology are important tools for virtual teams to externalize tacit knowledge (Perret \& Santoro, 2004). Externalization transforms tacit knowledge to explicit knowledge for learning and reuse by the virtual team. Externalization presents complexities attributable to the difficulty to transfer experiences from the individual's mind. Stories coupled with technology have the potential to lessen the tacit knowledge transfer barrier.

\section{CONCLUSION}

The virtual team operates in a complex and dynamic paradigm. For effective knowledge management virtual teams should build a community of practice to foster knowledge creation and sharing and to build trust (Davenport \& Prusak, 1998). Another key factor in virtual team performance is technology and practices to substitute for face-to-face meetings, and to establish a sharing culture and collaborative team dynamics. Knowledge management for engineering projects, software development and other collaborative project models depends on individual and team knowledge (Wang et al, 2005).

Chase (2015) asserts in the book Peers, Inc. that diverse networked peers such as virtual teams has important implications for the future world. Virtual teams with a culture of collaboration and trust allow people to share knowledge to help each other. Virtual teams support continuous learning and gaining wisdom from tacit knowledge and collective experiences (Chase, 2015).

Knowledge management has become increasingly important to organizations as the paradigm of life long employment at one or two firms has shifted. Future workers will have a minimum of 5 employers in their career. The multiple employer trend, coupled with the large number of retirements expected over the next $5-10$ years, has fostered a sense of urgency to retain and rapidly grow organizational knowledge. Organizations must accept the shortened tenure for the worker and prepare new strategies to proactively address potential knowledge erosion. In China, the accepted practice is knowledge is not owned by the company but is an individual resource to be shared among companies. Tacit knowledge, the rich experiential knowledge that is difficult to transfer, is in the individual's mind. Further research on technology and gamification as enablers for knowledge management, communities of practice and other teaming models to foster tacit and explicit knowledge creation and transfer is necessary as the workforce changes. 


\section{REFERENCES}

Alavi, M., \& Leidner, D. E. (2001). Review: Knowledge management and knowledge management systems: Conceptual foundations and research issues. MIS Quarterly, 25(1), 107-136.

Bosch-Sijtsema, P. M., Ruohomäki, V., \& Vartiainen, M. (2009). Knowledge work productivity in distributed teams. Journal of Knowledge Management, 13(6), 533-546.

Bosch-Sijtsema, P. M., Fruchter, R., Vartiainen, M., Ruohomäki, V., Chalmers University of Technology, Department of Civil and Environmental Engineering, Construction Management, ... Chalmers tekniska högskola. (2011). A framework to analyze knowledge work in distributed teams. Group \& Organization Management, 36(3), 275-307. doi:10.1177/1059601111403625

Chase, R. (2015). Peers Inc: How people and platforms are inventing the collaborative economy and reinventing capitalism.

Chin-Bin, Wang.,Yuh-Min Chen., Jen Chen., Chengter, Ho. (2005) Methodology and system framework for knowledge management in allied concurrent engineering, Computer Integrated Manufacturing, (18)1, 53-72

Cummings, J., \& Dennis, A. R. (2018). Virtual first impressions matter: the effect of enterprise social networking sites on impression formation in virtual teams. MIS Quarterly, 42(3), 697-718.

Curtis, A. M., Dennis, A. R., \& McNamara, K. O. (2017). From monologue to dialogue: performative objects to promote collective mindfulness in computer-mediated team discussions. MIS Quarterly, 41(2), 559-581.

Davenport, T. H., 1954, \& Prusak, L. (1998). Working knowledge: How organizations manage what they know. Boston, Mass: Harvard Business School Press.

Dávideková, M., \& Hvorecký, J. (2016, September). Collaboration tools for virtual teams in terms of the SECI model. In International Conference on Interactive Collaborative Learning (pp. 97-111). Springer, Cham.

$\begin{array}{lllll}\text { Deloitte } & \text { Tech } & \text { Trends } & \text { forom }\end{array}$ https://www2.deloitte.com/content/dam/Deloitte/sv/Documents/technology/Tech-Trends-2015.pdf

Hoffman, R., (2016). Using Artificial Intelligence to Set Information Free, MIT Sloan Management Review

Kanawattanachai, P., \& Yoo, Y. (2007). The impact of knowledge coordination on virtual team performance over time. MIS Quarterly, 31(4), 783-808.

Nonaka, I., \& Takeuchi, H. (1995). The knowledge-creating company: How japanese companies create the dynamics of innovation. New York: Oxford University Press.

Pawlowski, J. M., Bick, M., Peinl, R., Thalmann, S., Maier, R., Hetmank, L., . . Pirkkalainen, H. (2014). Social knowledge environments. Business \& Information Systems Engineering, 6(2), 81-88. doi:10.1007/s12599014-0318-4

Perret, R., Borges, M. R. S., \& Santoro, F. M. (2004). Applying group storytelling in knowledge management. Lecture Notes in Computer Science (Including Subseries Lecture Notes in Artificial Intelligence and Lecture Notes in Bioinformatics), 3198, 34-41.

Polanyi, M., \& Sen, A. (2009). The tacit dimension (University of Chicago Press ed.). Chicago: The University of Chicago Press.

Rai, R. (2011), Knowledge management and organizational culture: a theoretical integrative framework. Journal of Knowledge Management, p 779-799.

Semerádová, T. (2015). Using online platforms to solve knowledge transfer problems in projects. International Review of Management and Business Research, 4(4 Part 1), 1010.

Thomas, D., \& Bostrom, R. (2010). Building trust and cooperation through technology adaptation in virtual teams: Empirical field evidence 1. Edpacs, 42(5), 1-20. doi:10.1080/07366981.2010.537182

Wang, C., Chen, Y., Chen, Y., \& Ho, C. (2005). Methodology and system framework for knowledge management in allied concurrent engineering. International Journal of Computer Integrated Manufacturing, 18(1), 53-72. doi: $10.1080 / 09511920412331284753$

Winston, P. H. (2011). The strong story hypothesis and the directed perception hypothesis. Paper presented at the FS11-01, 345-352.Winston, P. 